Vol. 40(2), pp. 74-81, Dec. 2021

ISSN 1821-536X (print)

ISSN 2619-8789 (electronic)
Tanzania Journal of Engineering and Technology

Copyright $(\subset) 2021$ College of Engineering and

Technology, University of Dar es Salaam

Full Length Research Paper

\title{
Economic Analysis of Islanded Microgrid: A Case Study of Kisiju Village - Coastal Region
}

\author{
Eva Mnyanghwalo, Irene H. Masenge, Jackson J. Justo*, Francis Mwasilu \\ Department of Electrical Engineering, College of Engineering and Technology, \\ University of Dar es Salaam, TANZANIA \\ *Correspondent: justo.jack@udsm.ac.tz
}

\begin{abstract}
The concept of Microgrid $(M G)$ has gained significant attention of researchers and projects on the business side of electrical power generation and utilization, particularly in electrification of islanded areas such as villages. Most of these microgrids are powered by renewable energy resources (RERs) and they distribute power in low voltage distribution networks. Hence, these systems are faced with reliability problems due to the intermittency nature of RERs which affect the technical as well as the return on Investment of specific projects. In the latter context, reliability and economic analysis of the MG systems is an inevitable choice. This paper presents an economic and reliability analysis of the solar $P V(S P V) M G$ system installed at Kisiju village, located in the Coastal area of Mkuranga district in Tanzania, where operational costs, running costs and return value on investment of the installed MG system is discussed and analysis of the reliability of the system to consumers is performed and the results are validated using HOMER software.
\end{abstract}

Key words: Renewable Energy Resources (RERs), Distributed Generation (DG), islanded, Microgrid (MG), reliability and economic analysis, Solar Photovoltaic (SPV).

\section{INTRODUCTION}

A reliable electrical energy is very vital for socio-economic development of any community. Conventionally, this has been achieved through a centralized national grid which can also be interconnected to other power pools. However, electrification of islanded areas through this modality has been challenging, particularly in terms of the cost of erection and setting up the network, which thus paved the way to the concept of Microgrids. These MGs are advantageous in terms of reduction of losses as they remove the need for transmission network which therefore reduces the cost of electrical energy unit. Moreover, most of the MG are powered by RERs which provides further benefit of providing clean energy and reduction of destruction of the environment as opposed to the conventional methods which involve burning of fossil fuels which emit gases that detriment the ozone layer and contributes to global warming. However, RERs are intermittent in nature, hence posing reliability problems of the system. Therefore, on designing and building a power MG, sufficient economic and 
reliability analysis must be performed to ensure the overall and maxima economy of the project is achieved with as low per-unit cost of production as possible, as well as ensuring reliable electric energy is supplied (Paulo Moisés Costa, 2006) .The problem of determining the cost of production of electrical energy is highly complex and poses a challenge to power engineer since there are several factors that influence cost of production which includes land and equipment, depreciation of equipment, interest on capital investment etc,. (University, 2014)

In Tanzania, most of the existing MGs are SPV based due to the abundance availability of solar energy. Moreover, the vast use of SPV MGs in rural areas is fueled by short construction period, low operational complexity, and fuel price independency. This makes solar energy technology to be the most growing Renewable Energy Technology (RET) in Tanzania followed by wind energy.

This paper articulates the economic and reliability analysis of an islanded SPV microgrid located at Kisiju village in the Coastal Region in Tanzania. In depth information of the SPV MG in consideration is provided in section 2, while economic and reliability analysis of the system is presented in section 3 and conclusion is drawn in section 4.

\section{METHODS AND MATERIALS}

\section{Description of Study Area}

Figure 1 below presents the picture of the installed microgrid in Kisiju village. This is a microgrid built at Kisiju village, which is a part of the Coastal region in Tanzania and the electricity that was produced and distributed was capable of electrifying approximately sixty-eight (68) houses. Figure 2 provides the on-site SPV MG configuration located at Kisiju village. The system is comprised of SPV panels, Battery Energy Storage System (BESS) which is used to buffer the system and increasing reliability of the MG, inverters and distribution system. The inverters are well designed under coordinated control with the BESS to ensure system stability is maintained.

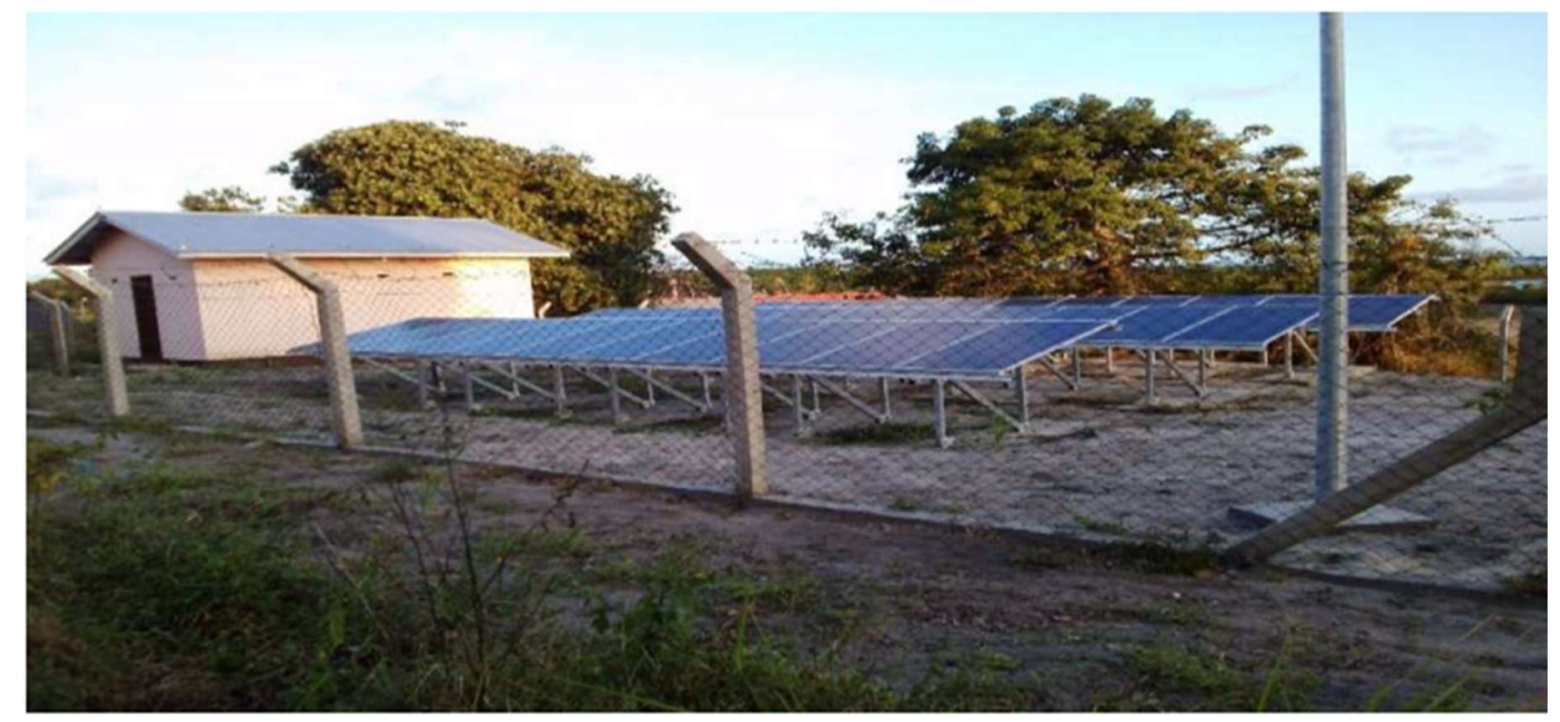

Figure 1: Installed micro grid with solar panels PV, at Kisiju (photo taken at Kisiju during a visit done in February 2019). 


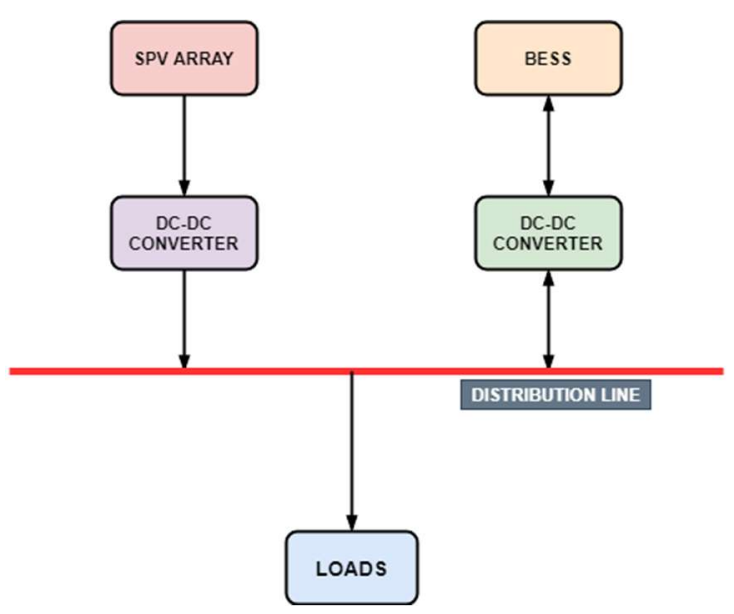

Figure 2: SPV MG architectural layout

\section{ECONOMIC ANALYSIS}

The concept of economic analysis was developed at the beginning of the 20th Century (Jiang, 2013) and it was applied in different industries. It is now commonly applied in the evaluation of cost efficiency of various projects including highway and bridge projects. It is a critical component of a comprehensive project or program evaluation methodology that considers all key quantitative and qualitative impacts of investments. It allows projects to identify, quantify, and evaluate the economic benefits and costs of energy in the considered project. The objective of the analysis is to ensure that the scarce resources are utilized in the best way, in terms of maximizing benefits to the public. It is important in the electrification process that cost-benefit for the entire life-cycle of the MG are properly evaluated. Therefore, energy vendors are responsible to make use of measures such as net present value of costs and benefits, benefit-cost ratio, and the internal rate of return to compare different competing alternatives. The alternatives that give the highest net present value, benefit-cost ratio, or return on investment are selected and placed to be funded, programmed, and eventually implemented. The cost of items in the economic analysis includes but are not limited to capital cost, operating cost, maintenance cost, preservation cost, Annual Interest Rate and project lifetime.

\section{Different Methods of Economic Analysis}

Economic analysis involves assessing or examining project from an economist's perspective. Economic analysis is also known as the study of economic systems or a production process or an industry which aims to determine how effectively the economy within it is operating. Economists say that economic analysis is a systematic approach to find out what the optimum use of scarce resources is. (Ahshan, 2017)

There are many ways to calculate and analyse the economic viability of the MG system. The capital costs of equipment and the operation and maintenance costs must be combined in some manners and cost comparison is made between installing and not installing the system. Here are some methods that can provide a start up on financial evaluation of a MG project. (Timofeev, 2017).

\section{Simple Payback Period}

This is one of the most common ways that evaluates economic value of a MG system. It is just a ratio of the extra first costs, $\Delta \mathrm{P}$, to the annual savings, $\mathrm{S}$. It has an advantage of being the easiest, understandable approach of all economic measures. However, it faces a problem of being one of the least convincing ways in presenting advantages of a project (Tool, 2018).

\section{Initial (Simple) Rate of Return}

The initial rate of return is just the reverse of the simple payback period, that is the ratio of the annual saving of a project (MG) to the extra initial investment.

\section{Internal Rate of Return (IRR)}

IRR is the most persuasive measure of the value of an energy-efficiency or micro-grid project. It allows the energy investment to be directly compared with the return that 
might be obtained for any other competing investment. IRR is the discount rate that makes the net present value (NPV) of the energy investment equal to zero.

\section{Economic Analysis by HOMER SOFTWARE}

HOMER is an abbreviation of Hybrid Optimization Model for Electrical Renewable. It is a micro power optimization model that simplifies the task of evaluating designs of both off-grid and grid-connected power systems for various applications. It can be used for designing and analyzing hybrid power systems, which contain a mix of conventional generators, co-generation, wind turbines, solar photovoltaic, hydropower, batteries, fuel cells, biomass and other inputs. It is a global standard software for optimizing $\mathrm{MG}$ design in all sectors, from the islanded power systems to the grid-connected campuses and military bases. Originally it was developed at the National Renewable Energy Laboratory, and then enhanced and distributed by HOMER Energy. It (HOMER) nests three powerful tools in one software-product, so that engineering and economics work side by side (Energy n.d.). Therefore, apart from the mathematical measurement of economic and reliability analysis, HOMER can be used to provide the same analysis as well. Hence, in this research HOMER Energy Software is deployed in making economic and reliability analysis.

\section{Economic Analysis of Kisiju SPV MG}

Every system needs to be economically feasible in order to be accepted by the project implementers and consumers of the product. The economic analysis of an MG system is based on the total Net Present Cost (NPC), Levelized Cost of Energy (COE) and Operating Cost (OC) of the system. Table 1 below presents the secondary data which was obtained from an islanded SPV MG at Kisiju. The economic analysis of this $\mathrm{MG}$ is discussed in the subsequent section:

\begin{tabular}{|c|l|l|}
\hline $\begin{array}{c}\text { Table 1: } \\
\text { Calculated } \\
\text { Localized } \\
\text { Cost of } \\
\text { Energy } \\
\text { (LCOE)S/N }\end{array}$ & $\begin{array}{l}\text { Parameter } \\
\text { Descriptions }\end{array}$ & Cost (TZS) \\
\hline $\mathbf{1}$ & Capital cost & $241,975,366$ \\
\hline $\mathbf{2}$ & $\begin{array}{l}\text { Operational } \\
\text { cost }\end{array}$ & $3,000,000$ \\
\hline $\mathbf{3}$ & $\begin{array}{l}\text { Replacement } \\
\text { costs }\end{array}$ & $4,281,550$ \\
\hline
\end{tabular}

LCOE is a standard measure for production costs in the energy sector, it approximates the (constant) price at which a plant must sell electricity over its lifetime to break even. It is expressed mathematically by the following equation;

$\mathrm{LCOE}_{\mathrm{k}}=(\mathrm{K} \times \mathrm{CRF}) /(8760 \times \mathrm{CF})$

where K-Initial cost, CF-Capacity factor $80 \%$, and

CRF-Capital recovery factor which is given by

$$
\mathrm{CRF}=\left(\mathrm{r} \times(1+\mathrm{r})^{\wedge} \mathrm{N}\right) /\left((1+\mathrm{r})^{\wedge} \mathrm{N}-1\right)
$$

8760-number of hours per year r-interest rate selected between $10 \%$

$\mathrm{N}$-Lifetime taken 5 years

By calculation, the localized cost of electricity at Kisiju SPV MG is approximately equal to $425.53 \mathrm{TZS} / \mathrm{kWh}$.

\section{Economic analysis of the SPV MG at Kisiju using HOMER Software}

Table 2 provides the economic analysis of the Kisiju SPV MG based on the HOMER software. Therefore, comparative analysis between handy calculations (LCOE) and HOMER's results is made, and it is found that;

LCOE is equivalent to TZS 673.9 in HOMER's simulation results while by handy calculation it is equal to TZS 423.53 which is $62.84 \%$ of the simulation price. 
Moreover, the operational cost from simulation results is found to be $14,536,000$, while by hand calculations, the operational cost for five years is at least $15,297,400$ which equals to $13.53 \%$ of its total cost.

\section{Economical and Reliability Analysis of the Kisiju SPV MG}

On preparations for a power or energy production project in any country, the national regulations must be followed without fail. In Tanzania, EWURA and TANESCO provide standards and regulatory guidelines with which energy vendors must comply. Upon adhering to the standards, the following subsection provides details on the basic requirements of the MG as well as their economic and reliability analysis.

\section{Micro Grid Basic Requirements}

\section{Capital cost required}

\section{CASE I}

For an MG of a capacity of $8.6 \mathrm{~kW}$, the following are the basic and fundamental requirements;

- Materials and structural construction$218,475,366 /=$

- Installation charge-23,500,000/=

- Operation costs (Salary for 1 technical personnel, 1 guard, 2 revenue persons) $(=100000 /=+50000 /=+30000 /=)=210,0$ $00 /=$ per month $=2,520,000 /=$ per year

- Fixed maintenance costs $250,000 /=$ per year

Income generated 9,360,000/= per year

Return on Investment

\section{ROI}

Average Annual Accounting Profit

$$
\begin{aligned}
& \text { Average Investment } \\
& \text { ROI }=\frac{(17,607,536.60)}{241,975,366.00} \\
& \text { ROI }=-5 \%
\end{aligned}
$$

A negative return on the investment interprets that the investment properties are actually losing money. In this scenario where the costs have exceeded the income, the project will end up with less than what was initially invested, which is clearly something no project wants or expects would happen. A negative return on an investment does not necessarily indicate a failed investment. However, if the project is losing money from the investment property and does not respond immediately, it will face the risk of a complete loss of the initial

\begin{tabular}{|c|c|c|c|c|}
\hline $\begin{array}{l}\text { Tariff } \\
\text { groups }\end{array}$ & Appliance & Qty & $\begin{array}{l}\text { Bill } \\
\text { per } \\
\text { mont } \\
\text { h } \\
\text { TZS } \\
\text { x } \\
1000\end{array}$ & $\begin{array}{l}\text { Bill per } \\
\text { year } \\
\text { TZS } \\
1000\end{array}$ \\
\hline A & $\begin{array}{l}2 \text { Lights, less } \\
\text { than } 10 \mathrm{~W} \\
\text { radio } \\
\text { and Mobile } \\
\text { Phone } \\
\text { Charging }\end{array}$ & 50 & 10.5 & 6,300 \\
\hline B & $\begin{array}{l}2 \text { Light, } \\
100 \mathrm{~W} \mathrm{TV}, \\
\text { less than } 10 \mathrm{~W} \\
\text { radio and } \\
\text { Mobile Phone } \\
\text { Charging }\end{array}$ & 8 & 40 & 3,840 \\
\hline $\mathrm{C}$ & $\begin{array}{lr}2 & \text { Lights, } \\
100 \mathrm{~W} & \mathrm{TV}, \\
\text { less } & \text { than } \\
10 \mathrm{~W} & \text { radio } \\
\text { and Mobile } \\
\text { Phone } \\
\text { Charging }\end{array}$ & 8 & 45 & 4,320 \\
\hline \multicolumn{3}{|c|}{ TOTAL COLLECTIONS } & 1,205 & 14,460 \\
\hline
\end{tabular}
capital invested in the investment property.

\section{CASE II: Income generated}

Using new Tariff which is $105 \mathrm{TZS}$ per $\mathrm{kWh}$ for $\mathrm{kWh}$ from $0-75 \mathrm{kWh}$ and $400 \mathrm{TZS}$ per $\mathrm{kWh}$ for $\mathrm{kWh}$ above 75 ;

Average Annual Accounting Profit

$$
\begin{aligned}
& \text { ROI }=\frac{(583,968.30)}{241,975,366.00} \\
& \text { ROI }=0.5 \% \\
& \text { ROI }=0.5 \text { Average Investment }
\end{aligned}
$$


From the calculations done above, the proper ROI is suggested to be from $0.1 \%$ to $1 \%$. This shows that an increase of $0.1 \%$ on prices, considering the running costs of a microgrid, will lead to an increase of $0.5 \%$ of the return on investment per year.

\section{SUMMARY}

\begin{tabular}{|l|l|}
\hline Item & Amount (TZS) \\
\hline Initial Cost/Average Investment & $241,975,366.00 /=$ \\
\hline Expected Annual Net Cash Flow & \\
\hline Revenue & $9,360,000.00 /=$ \\
\hline Less: Variable Cost & \\
\hline Operation Cost & $2,520,000.00 /=$ \\
\hline Gross Profit & $\mathbf{6 , 8 4 0 , 0 0 0 . 0 0} /=$ \\
\hline Less: Fixed Cost & \\
\hline Fixed Maintenance Cost & $250,000.00 /=$ \\
\hline Profit before tax & $\mathbf{6 , 8 1 5 , 0 0 0 . 0 0 / =}$ \\
\hline Less: Depreciation & $24,197,536.60 /=$ \\
\hline Average annual accounting profit & $\mathbf{( 1 7 , 3 8 2 , 5 3 6 . 6 0} /=)$ \\
\hline
\end{tabular}

\section{ANALYZING THE SYSTEM}

Net Present Value (NPV)

Economic analysis uses the significant of NPV in a micro grid system. NPV rule is an accurate way to evaluate decisions, and the math behind it is a useful way to value companies. We calculate NPV as the present value of Residual Cash Earnings (RCE), instead of free cash flow, because it provides a similar NPV result but gives us a better insight into period performance and allows us to track progress after the investment is made.

Figure 3 below shows that the unit price of energy is more significant in the investment, because the LCOE of Kisiju SPV MG was $57.865 \%$ lower than the minimum allowed cost of energy from EWURA.

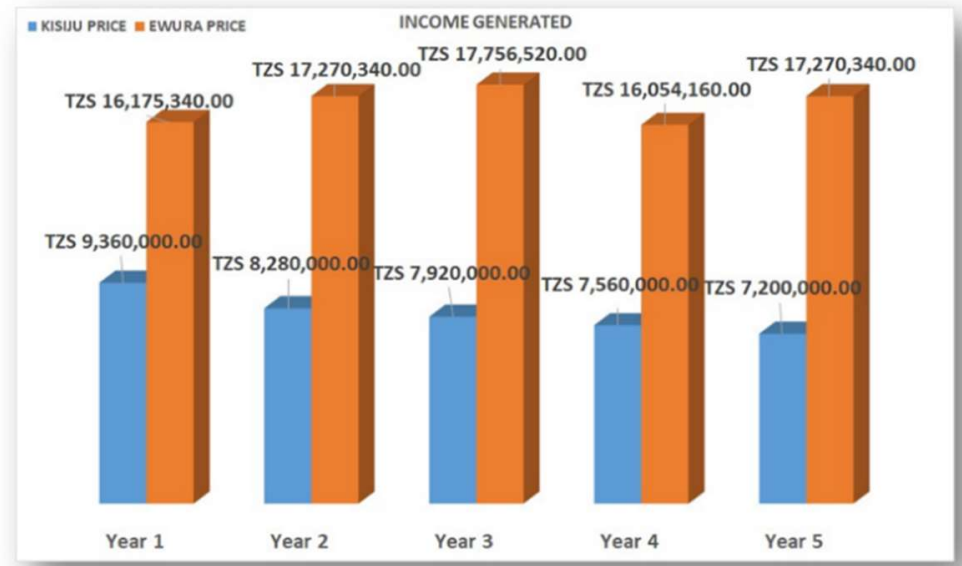

Figure 3: Graph of a generated income for 5 years of operations 


\section{Economic Analysis}

Economic analysis of the Kisiju SPV MG using the HOMMER software and mathematical method show that, the system has operated under loss for four years as it has been shown in HOMER Energy software results in Figure 4 below.

This has been caused by the following reasons;

- There was no proper strategy of revenue collection and cash flow for the project.

- There were no records documented on revenue collected and cash flow of the collected revenue.

- The cost of energy was settled under no considerations of return on investment. Hence the collected money was only for paying salary and allowances to the people who were taking care of the project.

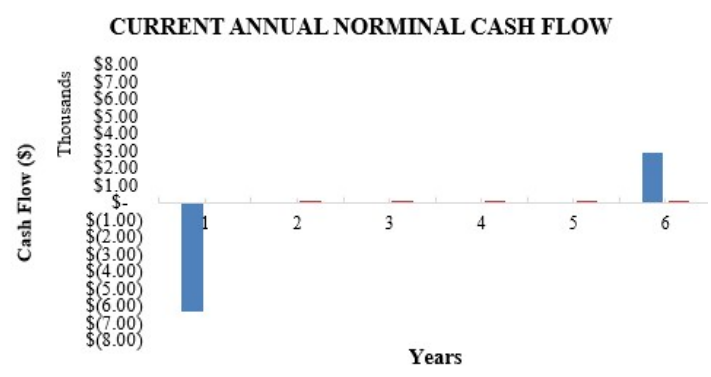

Figure 4: Kisiju MG cash flow for five years, as generated from HOMER software.

\section{CONCLUSIONS AND RECOMMENDATIONS}

Economical and reliability analysis is essential for viability analysis of any energy project before it is implemented. Critical and thorough analysis must be performed to ensure the return on investment is acquired as well as the cost of production of electrical energy in $\mathrm{MG}$ is minimal such that unit costs are affordable to consumers. Based on the analysis made above, it has been proved Kisiju SPV MG has been running under loss for first four years which lead to the project burning out on its fifth year of operations. Islanded MGs provides various benefits, therefore in order to enhance their business models in islanded areas, the following recommendations should be taken into consideration as far as economics of the MG systems is concerned:

\section{Recommendations on ways to Improve MG Economics}

- Developing a standard template for MG project cash flows, which will help in revenue collection and monitoring.

- Despite the energy tariffs used by the electric supply company, the responsible regulatory should also set specific tariffs for SPV MGs and other Renewable Energy (RE) systems, in which the tariff will be fair enough to allow a short even break of the invested capital.

Note: Even break is the point at which a project's total revenues equals to its total costs, at this point, the project is making a normal rate of return on its invested capital costs.

- The ministry of energy should consider developing funds for supporting the energy vendors who are interested in investing in rural electrifications programs, since the main hindrance of $\mathrm{MG}$ projects is lack of initial capitals.

\section{Suggested cost reduction techniques of micro grid system}

- Realistic feasibility study of the investment place where the project will be built and the coverage of places which will benefit from the same project.

- Being economic on approximation of total demand so that there will be no under quote or over quote. The effect of over quoting is the increase in the initial capital cost, which cannot be recovered easily in a short payback period.

To be economic on construction works which involve a series of civil works, getting cheap labor and precise approximations of the civil materials required for construction works should be considered. 


\section{REFERENCES}

Ahshan, Razzaqul, Iqbal, Tariq,Mann, G.K.I. Quaicoe, J.E. "Microgrid reliability evaluation considering the intermittency effect of renewable energy sources." International Journal of Smart Grid and Clean Energy, 2017: 259-268

Burke, Jim, and Annie-Marie Sahazizian. Electric Power Substation Engineering. Second Edition. Edited by John D. McDonald. New York: Taylor \& Francis Group, 2007.

Didier, FULCHIRON. "Protection of MV/ LV substation." Edited by Groupe Schneider. Cahier technique no192 (Collection Technique), July 1998:

Dorji, Tempa. "Reliability Assessment of Distribution." 2009.

Energy, HOMER.n.d.

https://www.researchgate.net/publication/2 63765594_Optimization_of_Renewabl e_Energy_Efficiency_using_HOMER/ download (accessed March 2nd, 2019)

Jiang, Y., G. Zhao, and S. Li. An. Economic
Analysis Methodology for Project Evaluation and Programming. Publication, 2013.

P.U. Okorie, U.O Aliyu, B. Jimoh, and S.M. Sani. "Reliability Indices of Electric Distribution Network System." Journal of Electronics and Communication Engineering Research (Quest Journals), 2015: 6.

Rural Energy Agency, National Bureau of Statistics. Energy Access Situation Report, 2016 Tanzania Mainland. Statistical Report, Dar Es Salaam: Rural Energy Agency, 2017.

Timofeev, R.A. \& Shlychkov, V.V. \& Nestulaeva, D.R. Methods of economic reliability assessment for industrial enterprise in the market economy conditions. SHS Web of Conferences. 35 .

01125.

10.1051/shsconf/20173501125. Russia: SHS Web of Conferences. 35. 01125. 10.1051/shsconf/20173501125., 2017, $1-4$. 